\title{
Kamu Hizmeti Yayıncılığında Markalaşma Yönelimi ve Piyasa İlişkileri Temelinde Ortaya Çıkan Çelişkiler
}

\section{Branding Orientation in Public Service Broadcasting and Contradictions on the Basis of Market Relations}

\section{Doç. Dr. Süleyman ilaslan ${ }^{1}$}

Başvuru Tarihi: 05.02.2019

Kabul Tarihi: 21.08.2019

Öz Neo-liberal politikalar ve hızl teknolojik gelişmeler temelinde 1980 sonrası süreçte yaşanan köklü dönüşümler medya sektörünü yeniden yapılandıran gelişmeleri de beraberinde getirmiştir. Kamu hizmeti yayıncılarının piyasayla ilişkilerinin giderek artması bu gelişmelerle yakından bağlantılıdır. Bu durum, kendi temel ilke ve değerlerine bağlı kalma ile piyasa koşullarına uyum sağlayarak varlıklarını sürdürme çabaları arasındaki gerilimli ilişkiyi her geçen gün daha fazla hissetmelerine yol açmaktadır. Son yıllarda yaygınlaşmaya başlayan markalaşma çabaları da bu gelişmeler temelinde değerlendirilmesi gereken bir yönelim olarak ortaya çıkmaktadır. Bu eğilimin yansımaları kamu tekellerinin kırıldı̆̆ı ve kamu hizmeti yayıncılarının piyasa aktörleriyle rekabet etme gerekliliği duymaya başladıkları tüm ülkelerde giderek ön plana çıkmaktadır. Özellikle, küresel medya yapılanmasının hâkimiyetinde kamu hizmeti yayıncılarının markalaşma çabaları uluslararası bir önem ve nitelik taşır hale gelmektedir. Bu çerçevede, çalışmada, medya sektörüne hâkim olan markalaşma eğiliminin kamu hizmeti yayıncılığında ortaya çıkış sürecine ve nedenlerine odaklanılmaktadır. Kamu hizmeti yayıncılarının markalaşma eğilimini benimseme nedenleri, markalaşma stratejilerinin ve ürettikleri markaların onlar açısından anlamı ve önemi sorgulanmaktadır. Bu noktada, kamu hizmeti yayıncılığının markalaşma eğiliminin yalnızca ekonomik öncelikler ve kaygılar temelinde ele alınmaması gerektiğine dair bir yaklaşım benimsenmektedir. Markalaşmanın kamu hizmeti yayıncılarının alandaki varlıkları ve konumlanma biçimleri açısından da önemli olduğu ileri sürülmektedir.

Anahtar Kelimeler: Kamu Hizmeti Yayıncılı̆̆ı, Piyasa, Markalaşma, Marka Yönetimi

\footnotetext{
1 Firat Üniversitesi İletişim Fakültesi, suleyman.ilaslan@gmail.com, ORCID: 0000-0003-4030-5100
} 


\section{Abstract}

The radical transformations in the post-1980 period on the basis of neo-liberal policies and rapid technological developmnets have brought developments that restructure the media sector. Increasing relations between public service broadcasters and the market in recent years are closely linked to these developments. This situation causes them to feel more the tense relationship between efforts of adhere to their fundamental principles and values, and of maintain the their existence by adapting to market conditions. The branding efforts which have become widespread in recent years have emerged as an orientation that should be evaluated on the basis of these developments. The reflections of this tendency are becoming increasingly prominent in all countries where public monopolies are broken and public service broadcasters are begining to feel the need to compete with market actors. In particular, the efforts of public service broadcasters to become a brand are becoming internationally important under the dominance of global media structure. In this regard, the study focuses on the process of the emergence of branding trend in public service broadcasting and its causes. The reasons why public service broadcasters adopt branding tendency, the meaning and importance of branding strategies and the their brands for them are questioned. At this point, an approach has been adopted that the trend of branding in public service broadcasting should not be considered solely on the basis of economic priorities and concerns. It is suggested that branding is important for public service broadcasters in terms of their existence and forms of positioning in media sector.

Keywords: Public Service Broadcasting, Market, Branding, Brand Management

\section{Giriş}

Medya sektörüne hâkim olan küresel ticari mantık ve dijital teknolojiler son ylllarda radyo ve televizyon yayıncılığında yaşanan dönüşümleri belirginleştirirken, bu dönüşümler kamu hizmeti yayıncılığının değişimler geçirdiği ve yoğun bir biçimde tartışma konusu edildiği bir süreci de beraberinde getirmektedir. Özellikle kamu hizmeti yayıncılarının geleceği, yeni koşullarda kendilerini konumlandırma ve yeniden tanımlama biçimleri gibi temel konular etrafında sürdürülen tartışmalar bu yayıncıların mevcut koşullara verdiği yanıtlar ve benimsediği yeni yayıncılık politikaları ile daha da artmaktadır. Murdock'un tabiriyle endüstriyel kapitalizmden bilgi kapitalizmine dönüşen dijital dünyada medya sektöründeki ticarileşme ve yoğunlaşma artarken kamunun ihtiyaçlarına cevap verecek bir kamu yayıncılığ modeline her zamankinden daha fazla ihtiyaç duyulması (2018, s.45) bu tartışmaları daha önemli kılmaktadır. Bu anlamda, kamu hizmeti yayıncılarının mevcut piyasa koşullarında ve teknolojik gelişmeler temelinde önemlerinin arttığına dair ve konumlarını kendi temel değerlerini terk etmeden yeniden şekillendirmeleri gerektiği yönündeki düşünceler ön plana çıkmaktadır (bkz. Martin ve Lowe, 2013; Murdock, 2004; Murdock, 2018; Steemers, 2003). Bunun temelinde ise kamu hizmeti yayıncılarının giderek daha fazla piyasa mantığına uyum gösteren bir yöneliş içinde olduklarına dair gözlemler yatmaktadır. Kamu tekellerinin kırılarak yayıncılık alanının özel teşebbüse açıldığı 1980 sonrası süreçte piyasa hâkimiyetinin ortaya 
çıkması kamu hizmeti yayıncılarını her geçen gün daha fazla rekabet ederek, ticari faaliyetlerini arttırarak ve markalaşarak alanın güçlü aktörlerinden birine dönüşme hedeflerine ve içeriklerini hâkim yayıncılık modeli temelinde üretme, popülerleştirme ve yaygınlaştırma gibi eğilimlere yönlendirmektedir. Bu anlamda kamu hizmeti yayıncılarının giderek piyasa ilkelerine dayanan bir yayınclık modelini benimsemeye başladıkları ve bir piyasa aktörüne dönüştükleri de en çok dillendirilen kaygılar arasında yer almaktadır (bkz. Moe ve Van den Bulck, 2013; Hoynes, 2003; Lowe ve Palokangas, 2010).

Son yıllarda bu köklü dönüşümlerin bir yansıması olarak tüm medya sektöründe markalaşma eğilimi ve çabaları ön plana çıkmaktadır. Bu durum kamu hizmeti yayıncılarını da markalaşma gerekliliğiyle baş başa bırakmaktadır (bkz. Hoynes, 2003; Johnson, 2007; Johnson, 2013; Lowe ve Palokangas, 2010). Kamu hizmeti yayıncılarının markalaşmayı önemsemeye başlamaları ve bu hedef temelinde belirgin adımlar atmaları kamu hizmeti yayıncilığına dair yukarıda değinilen kaygılar ve çelişkilerin belirginleştiği en temel noktalardan birini oluşturmaktadır. Bu kapsamda çalı̧̧ma, markalaşmanın kamu hizmeti yayıncılığı alanında ortaya çıkış nedenlerine ve bunun kamu hizmeti yayıncıları açısından anlamı ve rolüne odaklanmaktadır. Çalışmada temel olarak kamu hizmeti yayıncılığı alanında 2000 'li yılların başlarından itibaren ortaya çlkmaya başlayan markalaşma eğilimi ve çabalarını 1980 sonrası süreçte medya sektörünü yeniden yapılandıran temel değişimlerle yakından bağlantılı olduğu düşüncesi benimsenmektedir. $\mathrm{Bu}$ anlamda, serbest piyasada tüm şirketler açısından adeta bir zorunluluk haline gelen markalaşmanın kamu hizmeti yayıncllğının hedefleri arasına girmesinin de kaçınılmaz bir gereklilik olarak belirdiği ileri sürülmektedir. Yayıncılı̆̆ın ekonomik bir mantıkla ele alınması ve ticari bir faaliyet olarak değerlendirilmesinin kamu hizmeti yayıncılarının da markalaşmayı piyasadaki diğer ticari aktörlerle benzer bir çerçeveden ele almasına yol açtı̆̆ına işaret edilmektedir. Bununla birlikte, markalaşmanın medya sektörünün özellikle dijitalleşme temelinde giderek karmaşıklaşan ve çeşitlenen mevcut koşullarında kamu hizmeti yayıncılarının kendilerini tanımlama ve konumlandırmaları açısından da önem taşıdığına vurgu yapılmaktadır. Bu kapsamda, markalaşmayı yalnızca bir ekonomik değer yaratma süreci olarak değil aynı zamanda anlam üretim süreci olarak değerlendirmek gerektiğine vurgu yapan, markalaşmanın kamu hizmeti yayıncılarının izleyicileriyle ilişkilerini sürdürmeleri ve güçlendirmeleri açısından önem taşıdığını savunan bir yaklaşım benimsenmektedir. Bu yaklaşım kamu hizmeti yayıncılarının markalaşma çabalarında ve stratejilerinde hâkim piyasa mantığını temel alarak değil, sosyal sorumluluğu ve kamu hizmeti yayıncılığı ilkelerinden gelen köklü değerleri dikkate alarak hareket etmelerinin önemine işaret etmektedir (bkz. Johnson, 2013; Lowe ve Palokangas, 2010; Wæraas, 2008).

$\mathrm{Bu}$ yaklaşım temelinde çalışmada öncelikle kamu hizmeti yayıncılığının dönüşümüne temel oluşturan gelişmeler sorgulanmakta, kamu hizmeti yayıncıllğı ve piyasa ilişkileri temelinde ortaya çıkan yeni yapılanma biçimleri incelenmektedir. Ardından kamu hizmeti yayıncılarının markalaşma yönelimlerinin bu temel gelişmelerle bağlantıları ele alınmaktadır. Çalışmanın sonraki aşamasında kamu hizmeti yayıncıları açısından markalaşmanın neden önemli olmaya başladığına ve bu kurumların benimsediği markalaşma stratejilerine odaklanılmaktadır. Çalışmanın son kısmında ise hâkim piyasa mantığı temelinde şekillenen markalaşma 
yönelimleri ile kamu hizmeti yayıncllğının temel ilke ve değerleri arasındaki gerilimler incelenmekte, bu gerilimleri aşacak bir markalaşma biçimine dair değerlendirmeler yapılmaktadır. Bu anlamda çalı̧ma temel olarak kamu hizmeti yayıncılığında ortaya çıkan markalaşma eğilimine dair literatür üzerinden gerçekleştirilen kuramsal bir tartışma niteliği taşımaktadır. Bu tartı̧mada özellikle kamu hizmeti yayıncılı̆̆ının köklü tarihsel değerlerinin önemine işaret eden, yeni koşullara uyum sürecinde tamamıyla piyasa mantığını benimsemenin sıkıntılarına dikkat çeken ve bu açıdan kamu hizmeti yayıncılarının diğer yönetimsel faaliyetlerinin yanı sıra markalaşma stratejilerinde de kamusal, kültürel ve eğitsel değerlerini korumasının önemini vurgulayan bir yaklaşımın izi sürülmeye çalışılmaktadır.

\section{Kamu Hizmeti Yayıncılığının Hâkim Piyasa Koşullarıyla illişkileri}

Radyo tekniği ile başlayan elektronik yayıncilığın tarihsel gelişim sürecine baktığımızda karşımıza birbirinden farklı yayıncılık modelleri ve bunların kurumsallaşma biçimleri çıkmaktadır. Batı'da gerçekleşen bu biçimlenişlerin teknolojik gelişmelerin ötesinde piyasa, toplum ve kültürle kurulan ilişkiler çerçevesinde gerçekleștiği görülmektedir. bu anlamda, kamu hizmeti yayıncilığı modeli 1920'li yıllarda Avrupa'nın uygun tarihsel koşullarında piyasa mantığından uzak, kamusal finansman biçimiyle ve kamusal ve kültürel amaçlar ön plana çıkartılarak oluşturulmuştur. Bu temelde müşteriden ziyade vatandaş olarak konumlandırılan

dinleyicilerin kaliteli programlarla dengeli bir biçimde eğitimi, eğlendirilmesi ve bilgilendirilmesi hedefleri ön planda yer almıştır (bkz. Curran ve Seaton, 2003, s.106-122; Scannell, 2001, s.11-17).

Uzun tarihsel süreç bu modelin kamu yararı ve kamu hizmeti gibi ilkeler temelinde üstlendiği sorumlulukları hayata geçirme potansiyeli çerçevesinde sürekli yeniden ele alınmasına, eleştirilmesine ve yoğun tartışmaların konusu olmasına yol açan gelişmelere tanıklık etmiştir. Özellikle 1980 sonrasında ekonomik, siyasi ve toplumsal-kültürel alanlarda yaşanan köklü dönüşümler kamu hizmeti yayıncılığına dair canlı bir değişim ve tartışma ortamını beraberinde getirmiştir. Günümüze kadar uzanan bu süreçte kamu hizmeti yayıncılığının ele alındığı en temel tartışmalar bu sorumluluğu üstlenen kurumların varlığı, meşruiyeti, finansmanı ve piyasa ile olan ilişkileri gibi temel konular etrafında şekillenmiştir. Tartışmalar bu modeli benimseyen yayıncı kurumların kendilerini yeni yayıncilı ortamında nasıl konumlandıracakları, yeni medya teknolojilerine nasıl adapte olacakları, kurumsal olarak nasıl bir yönetim anlayışı benimseyecekleri, değişen toplumsal-kültürel ortamda izleyicilerle ilişkilerini nasıl yeniden şekillendirecekleri ve bu konumlandırma sürecinde bir yandan sahip oldukları değerleri korurken diğer yandan da hâkim piyasa koşulları ile nasıl bir iliş̧i biçimi geliştirecekleri etrafinda sürdürüle gelmektedir (bkz. Bardoel ve d'Haenens, 2008; Born, 2003; Collins, 1993; Enli, 2008; Moe, 2010; Murdock, 2005; Steemers, 1999).

Bu kapsamda, kamu hizmeti yayıncılı̆̆ının piyasa ile olan gerilimli ilişkisi ile kamu hizmeti yayıncılarının giderek piyasa mantığı ve pratiklerini benimsemesi son yıllardaki literatürün en temel parçasını oluşturmaktadır (bkz. Donders ve Raats, 2015; Goddard, 2017; Herzog vd., 2017; Iosifidis, 2010; Van Den Bulck, 2015). Kamu hizmeti yayıncllğıının finansmanı üzerinden 
piyasayla etkileşimlerinin niteliği ve gerekliliği üzerine tartı̧̧malar ve bu kurumların piyasaya açılması yönünde beliren eğilim neo-liberal politikalar temelinde yayıncılı̆̆ın kültürel bir faaliyetten ziyade ekonomik bir uğraş olarak görülmeye başlandığı 1980'li yıllarla birlikte belirginleşmiştir. Thatcher ve Reagan hükümetlerinin serbestleşme ve özelleştirme politikaları temelinde 1980'li yıllar kamu hizmeti yayıncılığı modelinin piyasa mantığı karşısında gerilemesine yol açan ve piyasaya açılmasını zorunlu kılacak adımların atılmasını beraberinde getirmiştir. Kamu tekellerinin kırıldığı bu ortamda yayınclık alanında beliren karma yapılar varlığını sürdürmekle birlikte ticari girişim ve mantık kısa sürede hâkimiyetini ilan etmiştir. Ulusal rekabetin ve piyasa ilişkilerinin yanı sıra küreselleşme süreci temelinde giderek artan uluslararası rekabetle de baş başa kalan kamu hizmeti yayıncıları açısından piyasa yönelimli yapılanma ön plana çıkmaya başlamıştır (bkz. Bardoel ve d'Haenens, 2008, s.337-340; Born, 2003, s.775; Hoynes, 2003, s.119-121; Hujanen, 2004; Martin ve Lowe, 2013, s.19; Moe, 2010, s.209; Murdock, 2005).

$\mathrm{Bu}$ yapılanma, kamu hizmeti yayıncıllğında piyasa temelli bir yönetim anlayışının belirginleşmesine yol açmıştır (Born, 2003; Moe, 2010; Moe ve Van Den Bulck, 2013). Hallvard Moe ve Hilde Van Den Bulck’a göre, bu değişim temelde kamu hizmeti yayıncılarının yaşanan dönüşümlere cevap verme adına 1990'lar boyunca yaptıkları reformlar sonucunda giderek "girişimcilik tarzını" ve "iş-benzeri yönetim" biçimini ön plana çıkaran "Yeni Kamu Yönetimi" doktrinini benimseme eğilimi göstermelerinden kaynaklanmaktadır. Bu hâkim yaklaşım temelinde kamu hizmeti yayıncllı̆̆ açısından da kamunun müşteri olarak tanımlandığı, mutlak bir iyi olarak rekabetin övüldüğü ve piyasalaşmanın ve dış kaynaklardan gelir elde etme anlayışının teşvik edildiği bir yönetim biçimi ön plana çıkmaya başlamıştır. Böylece kamu hizmeti yayıncıları temel dayanakları olan "kültürel-eğitimsel mantığın rekabet, izleyici maksimizasyonu ve kanal markalaşması ile değiştirilmesinin de aktif bir katılımcısına dönüşmüşlerdir” (2013, s.59). Bu tutum kamu hizmeti yayıncilığına model oluşturan BBC'nin bile son yllarda piyasa pratiklerini ön plana çıkaran faaliyetlerinde ve markalaşmayı önemseyen adımlarında yansımasını bulmaktadır (bkz. Goddard, 2017; Moe ve Van den Bulck, 2013; Johnson, 2013; Murdock, 2018).

$\mathrm{Bu}$ süreçte, Georgina Born'dan hareketle söylendiğinde, yayıncıllk alanındaki oyunun yeni kuralları temelinde ticarileşmenin yalnızca bir gereklilik değil iyi bir şey olarak görüldüğü ve kamu hizmeti yayınclarının aynı anda hem ticari hem de ticari olmayan faaliyetlerle ilgilenmesinde hiçbir çelişki bulmayan bir yaklaşım hâkim olmaya başlamıştır (2003, s.780781). Oysa kamu hizmeti yayıncllığ şekillendirilirken ABD'deki gibi ticari bir yapının sorunlu yanları vurgulanarak temel bir çerçeve çizilmiştir. Bu kapsamda yayıncılığın özellikle kamusal, kültürel ve eğitsel rol üstlenecek bir yapıda şekillendirilmesine önem verilirken piyasa koşullarının bu tür bir yapılanmaya imkân tanımayacağına vurgu yapılmıştır (bkz. Curran ve Seaton, 2003; Scannell, 2001). Günümüzde kamu hizmeti yayıncılarının ayakta kalmalarının tek yolunun piyasayla uyumlanmalarına bağlı olduğu yönünde bir yaklaşımın hâkim kılınması bu kurumların kuruluş temelleriyle çelişkili bir ortamla baş başa kaldıklarını göstermektedir. Özellikle kamu hizmeti yayıncılarını piyasa koşullarını ve mantığını benimsemeye yönlendiren yayıncılık politikalarının ön plana çıkması bu çelişkili yapıyı daha da görünür kılmaktadır. Bu 
hâkim yapılanma içinde bir yandan kamu hizmeti yayıncıları için yeni imkânlar ortaya çlkarken, diğer yandan da hareket alanlarını daraltan ve rekabeti temel alan bir yayıncılık politikasına yönelmelerine yol açan koşullar belirginleşmektedir (Murdock, 2018, s.44-45). Bu koşullarda kamu hizmeti yayıncılarının piyasaya bakışları ve etkileşimleri de bulanıklaşmaktadır. Hoynes'dan hareketle söylendiğinde, kamu hizmeti yayıncıları açısından bu temel algı bozulması "kamu hizmeti yayıncılarının ticari medya şirketlerini kendilerinin alternatif yayıncılık hizmeti sağladıkları bir yayınclık modelinin temsilcileri olarak değil, pazar payı için yarıştıkları rakipleri olarak görmelerinden" kaynaklanmaktadır (2003, s.126). Bu anlamda, kamu hizmeti yayıncıları açısından piyasa aktörü gibi davranmak ve piyasa pratikleri ile hareket etmek kaçınılmaz bir yönelim olarak değerlendirilmektedir. Son yıllarda kamu hizmeti yayıncılarının benimsedikleri markalaşma yönelimi de bu temel ilişkilerle bağlantılı olarak şekillenmektedir. Kamu hizmeti yayıncıları markalaşma hedefini önemseyen yeni yönetim anlayışlarıyla hem piyasa koşullarında varlıklarını sürdürme hem de meşruiyet zeminlerini sağlamlaştırarak sektörün önemli bir aktörüne dönüşme hedeflerine yönelmektedirler.

\section{Medya Sektöründe Markalaşmanın Artan Önemi ve Kamu Hizmeti Yayıncılarının Markalaşma Yönelimi}

1980 sonrasının piyasa temelli politikaları serbest piyasada faaliyet gösteren tüm şirketler için markalaşmanın öneminin artmasına ve bu temelde birer marka kimliği inşa ederek bunları tüketicilere ve izleyicilere aktarma çabalarının yoğunlaşmasına yol açmıştır (Arvidsson, 2006, s.3-4, 7; Moor, 2007, s.33-34). Deregülasyon politikaları ve dijital teknolojilerin sağladığı olanaklar temelinde ticari ve küresel medya yapısının hâkimiyetini ilan ettiği bu süreçte rekabeti temel alan piyasa koşulları medya sektöründe de belirginleşirken bu sektörde faaliyet gösteren kuruluşlar da kısa sürede markalaşma yönelimini benimsemiş, hatta bu koşullarla baş başa kalan kamu hizmeti yayıncıları açısından da markalaşma giderek önemli hale gelmeye başlamıştır (bkz. Born, 2003; Hoynes, 2003; Johnson, 2007; Johnson, 2013; Lowe ve Palokangas, 2010). Johson'u izlediğimizde bu süreçte markalaşmanın önemini arttıran koşulları ortaya çıaran üç temel değişim karşımıza çıkmaktadır. Bunlar medya sektöründeki yoğunlaşma eğiliminin artması, abonelik ödemelerini ve öde-izle sistemlerini ön plana çıaran meta ilişkilerinin belirginleşmesi ve televizyonun dağıtılabileceği kanalların sayısındaki artıştır (2007, s.6). Bu temelde, Lowe ve Palokangas'in markalaşmanın "medyada yeni bir şey olmasa da, medya için oldukça yeni olduğu"na işaret etmeleri ve medya şirketleri arasında markalaşma yöneliminin 1990'ların ikinci yarısından itibaren yaygınlaştığına vurgu yapmaları dikkate değerdir (2010, s.129). Bu tarih, Johnson'un bahsettiği koşulların sektörde belirginleşmeye başladığı dönemi kapsamaktadır. Bunlarla bağlantılı olarak 2000'lerin başlarından itibaren kamu hizmeti yayıncıları arasında da markalaşmanın önemsenmeye başlandığı bir süreç ortaya çıkmıştır (Bardoel ve d'Haenens, 2008; Born, 2003; Hoynes, 2003; Hujanen, 2004; Jakubowicz, 2007; Lowe ve Palokangas, 2010).

Medya kurumlarının markalaşma yöneliminde piyasa ilişkilerinin hâkim olduğu sektörel yapılanmanın temel bir itici güç olduğu bu yöndeki adımların ilk önce ABD’nin piyasa temelli 
medya yapılanmasında başlamış olmasında, Avrupa'da ise piyasa mantığının hâkim olmaya başladığı 1990’lı yıllardan itibaren belirginleşmesinde yansımasını bulmaktadır (bkz. Lowe ve Palokangas, 2010). Bu anlamda, Avrupa'da 1980 sonrası sürecin serbest pazara dayalı politikaları temelinde gerçekleşen birçok kamu hizmetinin özelleştirilmesiyle ya da bu hizmeti yerine getiren kurumların rekabetçi pazarın bir aktörü olarak yeniden konumlandırılmalarıyla bağlantılı olarak (Gromark ve Melin, 2013, s.1100; Moor, 2007, s.34; Wæraas, 2008, s.207) kamu hizmeti yayıncıları arasında da belirgin bir markalaşma yönelimi ortaya çıkmışıı. Hoynes, benzer bir sürecin ABD'deki kamu yayıncısı açısından da gerçekleştiğini belirtmektedir. ABD'deki hâkim ticari yapılanma kamu yayıncısının ticari yayıncılık pazarına entegre olma, pazar yönelimli iş uygulamalarını benimseme ve "bir dizi ürün yelpazesinde marka kimliğini oluşturma" çabalarına girmesine yol açmıştır. Bu kapsamda Hoynes, ekonomik değer üretme anlayışına dayalı yeni sistemde kamu yayıncısı kurum için de markaların ve markalaşmanın en temel değer haline geldiğine vurgu yapmaktadır (2003, s. 117, 122-124). Arvidsson'dan hareketle söylendiğinde bu, daha temelde kamusal alanın ve faaliyetlerin markalaşmaya başlamasina yol açan bir süreçtir (2006, s.3). Farklı alanlarda hizmet veren birçok kamu kurumunun birer marka üreterek özel şirketlerle rekabet içine girmesi bu durumu daha da belirginleştirmektedir (Wæraas, 2008, s.207-208).

Küreselleşme süreci medya kuruluşları açısından markalaşmanın önemini arttıran bir diğer unsur olarak karşımıza çıkmaktadır. Medya şirketlerinin, diğer tüm markalar gibi, markalaşmayı "bugünün ulus-ötesi ekonomisinin akışlarını yapılandıran Küresel Entegre Ağlara istikrar ve tutarlılık sağlayan önemli bir yönetim aracı olarak" görmeleri bu yönelimlerini belirginleştirmektedir (Arvidsson, 2006, s.4). Küresel bir yapıya dönüşmeye başlayan yayınclık sektörü açısından markalaşmanın önemi de küresel ilişkiler ve işleyiş açısından belirginleşmeye başlamıştır. Bu doğrultuda İngiltere'den BBC, Avustralya'dan ABC ve İtalya'dan RAI gibi kamu hizmeti yayıncıları birer ticari işletmeci gibi küresel pazar alanına dâhil olmaya ve burada güçlü bir markaya dönüşme çabasına girmişlerdir. Son yıllarda, özellikle BBC bu konuda çok önemli ilerlemeler kaydederek yayıncılık alanındaki hâkim küresel markalardan birine dönüşmüştür (Johnson, 2013, s.31). Kurumun dünyanın en güçlü ve değerli ilk 500 küresel markası arasında kendisine sürekli yer bulmasının yanı sıra İngiltere'de de ilk 150 marka arasında ilk sıralarda yer alması bu durumun en açık göstergelerinden biri olarak karşımıza çıkmaktadır (bkz. Brand Finance Global 500, 2012; Brand Finance Global 500, 2018; Brand Finance United Kingdom 150, 2018). Bu gelişmeler ve BBC gibi öncü kamu hizmeti yayıncılarının konumu tüm dünyada kamu hizmeti yayıncılarının hem ulusal hem de uluslararası alanda güçlü birer markaya dönüşme istek ve hedeflerini belirginleștirmektedir.

Lowe ve Palokangas'a göre, mevcut koşullarda medya şirketlerinin diğer birçok endüstriden daha fazla kalite ve güvenilirliğe ihtiyaç duymaları da onlar açısından markalaşmanın önemini arttıran en temel unsurlar arasinda yer almaktadır (2010, s.129, 133). Hujanen, medya sektöründe artan güven ihtiyacının markalaşmayı kamu hizmeti yayıncıları açısından da önemli kıldığına daha 2004 yılında işaret etmektedir. EBU'nun stratejik analizine gönderme yapan Hujanen, bu analizde izleyiciler ve dinleyicilerin yeni teknolojiler ve dijitalleşme temelinde giderek çoğalan medya çeşitliliği karşısında güvenebilecekleri medyaya daha fazla 
ihtiyaç duymaya başladıklarına ve bu anlamda medya sektöründe "güven adası" olarak markalara daha fazla gereklilik duyulacağına vurgu yapıldığına dikkat çekmektedir (2004, s.150). Kamu hizmeti yayıncilarının artan rekabet ortamında kendi marka kimliklerini kalite ve güven üzerine kurma çabaları ve bunun için kamu hizmeti yayıncllı̆̆ anlayışının temel ilkelerine ve uzun tarihsel köklerine dayanma eğilimi göstermeleri bu açıdan dikkate değer bir gelişme olarak karşımıza çımaktadır (bkz. Debrett, 2009; Hoynes, 2003; Johnson, 2013; Lowe ve Palokangas, 2010).

$\mathrm{Bu}$ anlamda, kamu hizmeti yayıncıları açısından markalar izleyicilerin kanallarına ve farklı mecralardaki ürün ve faaliyetlerine bağlllı̆ını sağlayacak kaliteli hizmetler ile güven, değer ve itibarın sembolü haline gelmektedir (Born, 2005; Hoynes, 2003, s.214-215; Johnson, 2013, s.313). Örneğin Debrett, doğrulanmamış ve güvenilmez birçok bilginin yaygın bir dolaşıma girdiği günümüz dijital ve çevrimiçi medya ortamında güvenilir haberciliğin kamu hizmeti yayıncılarının kanal markaları için temel önemde olduğunu belirtmektedir (2009, s.810-811, 823). Sorensen de BBC ve Channel 4 özelinde, bu kanalların ürettikleri belgesellerin marka değerini geliştirmeye ve içeriklerin kamu hizmeti ilkeleri ve ciddiyeti temelinde üretildiğini göstermeye hizmet ettiğine işaret etmektedir (2014, s.36). Ancak, bu noktada, kamu hizmeti yayıncllğıını güven ve kalite temelli hizmet anlayışı üzerine inşa edilen markalaşma stratejilerinin kamu hizmeti fikrini metalaştırma potansiyeli taşılığının da gözlerden kaçmaması gerektiğine 1srarla vurgu yapıldığı görülmektedir (Hoynes, 2003, s.124; Johson, 2013, s.313, 315).

Markalaşmanın medya platformları boyunca tutarlı bir kimlik sağlamada önemli bir rol oynaması ise (Bennett ve Strange, 2008, s.114) kamu hizmeti yayıncilarına kalite ve güven üzerine inşa ettikleri kimliklerini diğer tüm faaliyetlerine yayma imkânı vermesi açısından önem taşımaktadır. Kamu hizmeti yayıncılarının bu durumun farkında olmaları markalaşma çabalarının artmasında temel rol oynamaktadır. Born, kanal sayısı, ürün ve faaliyet çeşitliliği sürekli artan BBC'de daha 2000'li yılların başlarında "markalaşmanın, çeşitlilikte temel bir birliği sağlayarak ve $B B C$ 'nin algısını güvenilir ve inanılır olarak güçlendirerek, BBC'yi rakiplerinden ayırmada hayati bir rol oynadığı konusunda bir mutabakat oluştu”ğuna vurgu yaparken tam da bu temel noktalara işaret etmektedir (2005, s.265-266). Bu çerçevede, EBU'nun analizi izlendiğinde de medya kuruluşları açısından markalaşmanın izleyicilerle kurulan ilişkileri geliştirmek ve görünürlüğü arttırmak için önemsendiğine dair benzer bir değerlendirmenin yapıldığı görülmektedir (bkz. Hujanen, 2004, s.150). Medya kuruluşlarının izleyici profilinin farklılaşması ve yeni medya teknolojilerinin ortaya çıkardığı olanaklar temelinde her geçen gün daha fazla kanal ve platforma yayılma çabası içine girerek ürettikleri çıtı miktarını arttırmaları markalaşma çabalarını önemli hale getirmektedir. Markalaşma eğilimi görünürlüklerini desteklemek, farklı alanlardaki faaliyetleri ve çıktıları arasındaki bağlantıları kurmak, kanalları ve ürünleri ile izleyicileri arasındaki ilişkileri geliştirmek ve izleyicilerin kuruma bağlılığını ve desteğini sürdürmeyi sağlamak açısından giderek daha fazla önem taşımaktadır (Bennett ve Strange, 2008, s.115-116; Hoynes, 2003, s.217; Hujanen, 2004, s.134, 137; Jakubowicz, 2010, s.15; Johnson, 2007, s.6-8; Johson, 2013, s.322; Sorensen, 2014). 


\section{Kamu Hizmeti Yayıncılarının Marka Yönetimi ve Markalaşma Stratejileri}

Markalaşmanın öneminin kabul edilmesi, sektörde faaliyet gösteren ticari kuruluşlar gibi, kamu hizmeti yayıncıları açısından da çeşitli markalaşma ve marka yönetimi stratejilerinin hayata geçirilmesini beraberinde getirmektedir. Bu süreçte kanalların markalaştırılması, medya çıktılarının ya da başka bir deyişle programların markalaştırılması, çapraz medya etkinlikleri ve tanıtım faaliyetleri ile bağlantılı alt markaların ve marka uzantılarının geliştirilmesi, alandan ya da alan dışından şirketlerle markalı içerikleri üretmek ve yaygınlaştırmak için ortaklıklar kurulması ve üretilen markaları izleyicilerle kurum arasındaki ilişkileri geliştirecek bir biçimde kullanmayı sağlayacak stratejiler oluşturulması ön plana çıkmaktadır (Hoynes, 2003, s.217; Johnson, 2007, s.11-20; Johson, 2013, s.325-326).

Markaların ait oldukları yapılar hakkında birer bilgi üretim araçları olarak dolaşıma girmeleri (Arvidsson, 2006, s.67) izleyicilerle ilişkileri sürdürme ve sağlamlaştırma açısından markalaşmaya ve markalaşma stratejilerine verilen önemi anlaşılır kılmaktadır. Günümüz piyasa koşullarında ticari faaliyetler kadar diğer kamusal faaliyetleri destekleyecek bilgi üretimlerine ve bu üretimi yönetecek yaklaşımlara da ihtiyaç duyulması markalaşmayı hem ekonomik hem de kamusal değerleri açısından önemli kılmaktadır. Markalaşmanın bu iki yönünden etkin bir biçimde yararlanmak kamu hizmeti yayıncıları açısından da kaçınılmaz bir hedef haline getirmektedir. Arvidsson'a göre "markalar, insan iletişimini yönetme ve programlayabilme yetenekleri ve bir değer kaynağı üretmeleriyle” önemli hale gelirler. Bu anlamda, marka yönetimi bir yönüyle kamusal iletişimi markanın gelişmesine ve yaygınlaşmasına imkân verecek biçimde yönetmekle ilgilidir (2006, s.13, 67). Bu noktada, markaların izleyicilerin deneyimleriyle ilişkisine değinmek önem taşımaktadır. Lowe ve Palokangas’a göre, bir markanın gücü ekonomik yatırımların ve ürünlerin yanı sıra izleyiciyle kurulan duygusal ilişkilere de bağlıdır. "Markalar sadece şirketin sahip olduğu şey değil; tüketicilerin benimsediği, yorumladığı ve yürürlüğe koyduğu şeydir.” Bu açıdan kamu hizmeti yayıncılarının günümüz medya ortamında oluşturdukları markalar ile izleyicileri arasındaki bağlantıları ve bağlılı̆̆ güçlendirmeye özen göstermeleri ayrı bir önem taşımaktadır (2010, s.132-133).

Giderek çeşitlenen ve farklılaşan yayıncılık pratikleri içinde izleyicilerle kurumun bağlantısını kurmak açısından içeriklerin markalaşmasını yönetmek bu anlamda temel bir önem taşımaya başlamıştır. Hujanen, programların markalaştırılma çabalarının temelinde yayıncılığın içerik odaklı bir anlayış temelinde şekillendirilme yöneliminin yattığını belirtmektedir (2004, s.134). 2000'li yıllardan itibaren belirginleşen içerik odaklı yayıncılık stratejileri, ki kamu hizmeti yayıncıları da bu stratejileri benimsemektedir, programların markalaşmasının önemini arttıran en temel unsurlardan biridir (Hujanen, 2004, s.134, 137; Johnson, 2007, s.8, 20). BBC'nin kanal ve hizmet markalarını genişletirken, bununla bağlantılı olarak özellikle BBC Worldwide temelinde yürüttüğü küresel çaptaki faaliyetleri çerçevesinde önemli gelirler elde ettiği Top Gear, Doctor Who ve Dancing with The Stars gibi markalaşmış programlar üretmesi buna örnektir (Johnson, 2013, s.322; Sorensen, 2014, s.40). Ancak Johnson'a göre, içeriklerin kendi başına bir marka olmasının beraberinde getirdiği temel sıkıntı program ile onu yayınlayan kurum arasındaki ilişkiyi kesmesinden kaynaklanmaktadır. Piyasadaki ticari aktörlerin bu 
programlardan gelir elde ettikçe bunu sorun etmemesine karşın, izleyicilerin kamu hizmeti yayıncılığına bağlllığı ve güvenini sağlamak için bu ilişkinin sürdürülmesinin kamu hizmeti yayıncıları açısından büyük önem taşıdığını vurgulamaktadır. Bu anlamda, BBC gibi bir kurumun markalaşmış nitelikli programlarını önce farklı platformlardan tüm izleyicilerine ücretsiz olarak sunmaya özen gösterdiğine ve bu programların ticari bir kaygıyla üretildiği fikrini oluşturacak adımlardan dikkatle kaçındığına işaret etmektedir. Ona göre, bu yayın biçimi programları BBC kanalları ve kurum markasıyla bağlantılandırmaya, programlarla ana marka arasındaki ilişkileri güçlendirmeye ve izleyicilerin kanala olan güvenini ve desteğini sürdürmeye de aracilık etmektedir (2013, s.322).

$\mathrm{Bu}$ çerçevede, medya kuruluşlarının ürettikleri markaları giderek çeşitlenen faaliyetleri ve çıktıları arasındaki bağlantıları kurmak için önemsedikleri, kamu hizmeti yayıncıları açısından ise bunun çok daha kritik bir rol üstlendiği söylenebilir. Celia Lury, markayı "ürünler ve hizmetler arasındaki ilişkiler dizisi”" olarak tanımlarken tam da markalaşmanın bu rolüne işaret etmektedir. Lury, bu durumun yayıncılıkta kanalların logoları etrafında karşımıza çıktığını belirtmektedir. Programlar arasındaki boşlukları dolduran logoların programlar içinde ve arasındaki çoklu ilişkileri mümkün kıldığını, hatta bu ilişkilerin yalnızca belli bir medya içinde değil medyalar boyunca ve arasında kurulmasına da aracılık ettiğini belirtmektedir. Ona göre "logo, konumlandırılması yoluyla, markanın sürekli değişen bir dizi ürün olarak tanınmasını mümkün kılmaktadır” (2004, s.1, 9, 74-75, 78). Bu ise bir kanalın farklı mecralara yayılan markalaşma stratejilerini bütünleştirmesini ve kendi temel markasıyla diğer bağlantılı markaları arasındaki ilişkileri sürdürmesini sağlaması açısından önem taşımaktadır. Son yıllarda medya sektöründe yaşanan yapısal değişim ve yeni medya mecralarının ürün çeşitliliğini ve faaliyet alanlarını genişletmesi logoların bu kullanımını giderek daha önemli hale getirmektedir. Johnson bu durumu BBC’nin kendi logosunu kendi kanalları, ürünleri ile diğer bağlantılı ticari kanalları ve ürünlerinde kullanım biçimleri üzerinden örneklendirmektedir. BBC'nin sahip olduğu bir dizi logonun kanallarından, programlarına kadar farklı biçimlerde ortaya çıktığını ve bunların izleyicilerin $\mathrm{BBC}$ markasıyla kurulan deneyimlerini şekillendirmede temel bir rol oynadıklarını belirtmektedir (2013, s.319).

Yakın zamana kadar televizyon kanallarının marka inşa etme çabalarının kanal logoları temelinde şekillenmesi söz konusu olmakla birlikte bu sınırlı markalaşma stratejisi sektörün yapısında meydana gelen ekonomik, kurumsal ve teknolojik değişimler temelinde hızlı bir gelişim ve farklılaşma sürecine girmiştir (Lowe ve Palokangas, 2010, s.129). Bu durumu piyasa aktörleriyle benzer stratejileri benimseyen kamu hizmeti yayıncılarının markalaşma adımlarında görmek mümkündür. Kamu hizmeti yayıncılarının markalaşma çabaları logolarını lisanslamanın ötesine, markasına ait içerikleri ve onlarla bağlantılı ürünleri üretmek ve yaygınlaştırmak için farklı alanlardan şirketlerle ve büyük medya şirketleriyle anlaşmalar yapma, farklı yeni medya platformlarına yayılma ve buralara uygun içerikler ve uygulamalarla marka ağını genişletme, yeni reklam biçimleri satma ve kurumla bağlantılı lisanslı ürün yelpazeleri geliştirerek kurumla anılacak yeni markalar oluşturma stratejilerine kadar uzanmaktadır (Hoynes, 2003, s.124-125; Johson, 2013, s.320-326; Lowe ve Palokangas, 2010, s.130-134). 1980 sonrasının bir ürünü olarak yaygınlaşan marka uzantıları dalgası kapsamında 
(Arvidsson, 2006), kendileriyle bağlantılı alt markalar üretmeleri de bu stratejiler kapsamına girmektedir. Örneğin BBC tüm hizmetlerine, kanallarına, medya platformlarına ve içeriklerine ait marka uzantıları oluşturmakta -BBC One, bbc.co.uk, BBC Worldwide, Good Food dergisi, BBC News, BBC Shop, BBC Costumes \& Wigs, BBC iPlayer vb.- ve bunların her birinin geçerliliği ve güvenilirliğini $\mathrm{BBC}$ ana markasının değer ve ilkelerine dayandırmaktadır (Johnson, 2013, s.320-321; Lowe ve Palokangas, 2010, s.130-131).

Bu süreçte kamu hizmeti yayıncılarının ticari faaliyetleri ile kamu hizmeti faaliyetleri arasında belirgin bir ayrım oluşturma ve markalarını da bu ayrım temelinde inşa ederek kullanma çabası içine girmeleri dikkate değerdir. Örneğin, Johnson, BBC’nin ticari faaliyetleri ile kamu hizmeti faaliyetleri arasında bir ayrım yapma konusunda büyük bir çaba gösterdiğine vurgu yapmaktadır. Markalaşma stratejileri ve oluşturduğu markaları kullanma biçimi de bu temelde şekillenmektedir. Ona göre, BBC’nin İngiltere'deki ticari kanalları BBC adını kullanmaktan kaçınırken izleyiciye aslında bir kamu hizmeti yayıncısı olarak BBC ile özdeşleştirmemeleri gereken ticari bir ürünle karşı karşıya oldukları söylenmekte ve BBC’ye kamu hizmeti yayıncılığı beklentisi çerçevesinde verilen kamusal desteğin sürdürülmesi sağlanmaya çalışılmaktadır. Bununla birlikte, uluslararası alanda faaliyet gösteren ticari uzantıları BBC markasını açık bir biçimde kullanarak BBC’nin öncü bir kurum olarak şekillendirdiği kamu hizmeti yayıncılığı imajından yararlanmakta ve bu sayede ürünlerinin uluslararası pazarlarda daha yaygın bir kabul görmesini garanti etmek istemektedirler (Johnson, 2013, s.317, 321). Bu çabalar, Lowe ve Palokangas'ın ürünlerin kalite olarak birbirine denk olmaya başladığı rekabetçi ortamda markalaşmanın farklılığı ortaya koymanın ve sunulan ürünlerin standart bir kalitede olduğunu garanti etmenin bir aracı olarak kullanıldığına yaptıkları vurguyu akıllara getirmektedir (2010, s.132). BBC’nin marka kullanım stratejileri örneğinde temel olarak içeriklerdeki farklılığın kamu hizmeti ilkelerine dayandırılan BBC markası çerçevesinde şekillendirilmeye çalışıldığı söylenebilir. Ancak, Goddard'ın BBC’nin son yıllarda önemsediği bu farklılığın piyasayla bağlantılı olarak ve eğlence ağırlıklı hâkim piyasa mantığının BBC programcilığı üzerindeki etkileri temelinde şekillendiğine vurgu yapması (2017, s.1090-1091) markalaşma sürecinde kurumun ticari/kamusal gerilimini belirgin bir biçimde yaşadığını göstermesi açısından önem taşımaktadır.

\section{Markalaşma Yönelimi ve Kamu Hizmeti Yayıncılığı Arasındaki Çelişkiler}

Markalaşma her ne kadar kamu hizmeti yayıncılarının medya sektörünün mevcut koşullarında varlık gösterme çabalarının bir parçası olarak ortaya çıkar ve bu anlamda onlara katkı yapar görünse de her zaman için onları kendi temel dayanaklarından ve ilkelerinden uzaklaştırma ve birer piyasa aktörüne dönüştürme riskini de taşımaktadır (Moe ve Van den Bulck, 2013, s.59; Hoynes, 2003, s.128). Çünkü, Arvidsson'un belirttiği gibi, maddi olmayan bir sermaye biçimi olarak markaların gündelik hayatın yanı sıra iletişimin ve medya içeriklerinin metalaştırılmasıyla ve şirketler ve kurumlar açısından bu tür bir yönelimin benimsenmesiyle yakın bağlantısı vardır (2006, s.7, 13). Kamu hizmeti kurumları kendilerini marka ürünler üreten, onları pazarlayan ve bu kapsamda tüketici olarak görmeye başladığı izleyiciler için diğer şirketlerle rekabet eden bir nitelikte konumlandırmaya yöneldikçe bu risk giderek artmaktadır 
(Hoynes, 2003, s.218; Moor, 2007, s.34). Bu yönelimi ABD Kamu Yayıncılığı Kurumu özelinde değerlendiren Hoynes’a göre, “markalaşma stratejisi 'eski Kamu Yayıncılığı Hizmeti'nin kültürel değerini 'yeni Kamu Yayıncılığı Hizmeti’ için finansal değere dönüştürme girişimidir. $\mathrm{Bu}$ değiş tokuş, kamu hizmetinin ve kamu hizmetine eşlik eden güvenin pazarlanabilir bir metaya dönüştürülmesinin bir aracıdır” (2003, s.128). Bu noktada, kamu hizmeti kurumlarının kamu hizmeti ilkeleri ve temel dayanakları üzerine inşa ettikleri güvenin piyasa da kullanılabilir bir değere dönüştürülmesine yapılan vurgu önemlidir.

Kamu hizmeti yayıncılığının dönüştüğü, kendisini yeni koşullara adapte etme ve konumunu yeniden tanımlama ihtiyacı duyduğu günümüzde karşı karşıya olduğu temel sorunlardan bir tanesi kamu hizmeti ilkelerinde temellenen faaliyetleri ile ticari faaliyetleri arasındaki ilişkileri nasıl bağlantılandıracakları noktasında dügümlenmektedir. Kamu hizmeti yayıncılarının markalaşma eğilimi ve çabaları tam da bu sorunun belirginleştiği bir alan olarak karşımıza çıkmaktadır. Marka kültürünün hakimiyetinin arttığı bir dönemde konuya kamu hizmeti yayıncılarının markalaşmaya önem vermelerinin bir gereklilik olduğu düşüncesi çerçevesinde pragmatik bir yaklaşımla baktıklarını belirten Lowe ve Palokangas buradaki temel sorunun markalaşmanın ön plana çıktığı "bu metalaştırılmış çerçevenin kamu hizmeti yayıncılığının benzersiz bir kâr amacı gütmeyen mirasa dayanan temel değerleri ile nasıl hizalanacağı" noktasında yattığına işaret etmektedirler (2010, s.129). Bu sorunlu nokta kamu hizmeti yayıncılarının markalaşma sürecine odaklanan diğer çalışmalarda da temel bir tartışma çizgisi olarak karşımıza çıkmaktadır (bkz. Hoynes, 2003; Hujanen, 2004; Johnson, 2013). Örneğin Johnson, günümüzde kamu hizmeti yayıncılarının ticari faaliyetlerini bu kurumların dayandıkları kamu hizmeti yayıncılığı anlayışını bozan temel unsur olarak reddetmek yerine bu kurumların "kamu hizmetleri ile ticari faaliyetleri arasındaki ilişkileri nasıl yöneteceklerini sormaya ihtiyaç" olduğunu belirtmektedir. Baskın bir ticari medya ortamında BBC’nin hiçbir ticari faaliyeti olmayan bir kurum olarak kalmasını beklemenin mümkün olmadığını, bunun yerine kamusal olarak finanse edilen yayıncılığın toplumsal ve kültürel değerini tartışmaya devam ederken, BBC gibi yayıncıların ticari ve kamu hizmeti faaliyetleri arasındaki ilişkiyi daha iyi bağlantılandırabilecekleri yollara bakmak" gerektiğine vurgu yapmaktadır (2013, s.316, 328).

Kamu hizmeti yayıncıları açısından bu gerilimli ve çelişkili durumun belirginleşmesi marka inşa etme sürecinin sosyal ve ekonomik ilişkiler temelinde şekillenen ikili doğasıyla yakından bağlantılıdır denilebilir (bkz. Advissor, 2006, s.4-5). Bu anlamda, bir yandan sosyal kültürel itibarlarını ve konumlarını ürettikleri markalarla güvence altına almaya çalışan kamu hizmeti yayıncılarının diğer yandan da markalarının ekonomik değeriyle ilgilenmeleri ve gelirlerinin bir kısmını bu sayede elde etme eğilimi göstermeleri kamu hizmeti yayıncılığı açısından markalaşma sürecini karmaşık bir yapıya büründürmektedir. Markalaşmanın piyasa koşulları içinde ve piyasa aktörü olarak hareket etme gerekliliğiyle yakından bağlantılı olması kamu hizmeti yayıncıları açısından çelişkili bir durum ortaya çıkarmaktadır. 1980 sonrası süreçte medya yapılarının ve kültürünün ticari niteliklerinin hâkimiyet kazanması karşısında kamusalkültürel yaklaşımlar temelinde şekillendirilen ve kâr amacı gütmeyen iletişim biçimlerinin gerilemesi bu sorunlu durumu belirginleştirmektedir. Örneğin, ABD’de kamu hizmeti yayıncılığının piyasa karşısında gerilediğine vurgu yapan Hoynes, markalaşmayı kamu hizmeti 
yayıncılarının giderek daha fazla piyasaya bağlı hareket etmesinin bir yansıması olarak değerlendirmektedir (bkz. Hoynes, 2010). Bu anlamda, kamu hizmeti yayıncılarının 2000'lerin başlarından itibaren "markalarından finansal olarak faydalanmalarını sağlayacak daha fazla ticari rol arayışına girmeleri" (Steemers, 2003, s.131) onlar açısından ticari ve kamusal faaliyetleri arasındaki gerilimi daha da belirginleştirmektedir.

Bununla birlikte, Johnson, yayıncılar açısından markalaşmanın dijital çağda temel bir strateji olarak yaygın kabul gördüğünü belirtmektedir. Ona göre, "markalaşma rekabet avantajını arttırmak için benimsenen bir ticari strateji olarak görülürken, aynı zamanda kamu hizmeti yayıncıları tarafından kamu hizmeti faaliyetlerini ve itibarlarını desteklemek için de kullanılmaktadır." Johnson'un bu vurgusu kamu hizmeti yayıncilarının bir yandan ticari faaliyetleri sürdürme gerekliliği duyarken diğer yandan da kamu hizmeti yayıncllı̆̆ ilkelerine bağlı kalma ve bu ilkeleri hayata geçirme gerekliliği arasında gerilimli bir markalaşma süreci içinde olduklarına işaret etmektedir. Dolayısıyla, markalaşma çabaları bu kurumlar açısından ticari faaliyetlerini desteklemenin çok ötesine, kuruluş temelleriyle bağlantılı kamu hizmeti ilkelerinden gelen değerleri koruma, itibarlarını sürdürme ve kamu desteğini ve kamu hizmeti yayıncllğ̆ına bağlllı̆̆ güçlendirme hedeflerine uzandığı ölçüde $(2013$, s.313, 315) bu gerilimi ve çelişkileri de belirginleştirmektedir. Bu anlamda, Johnson'un işaret ettiği, BBC'nin kendi ticari faaliyetlerini yönetmek için hazırladığ kılavuzlarda -özellikle Adil Ticaret Klavuzu (2012) ve Küresel Strateji (2011)- tüm ticari faaliyetlerinin uymak zorunda olduğu dört temel ticari kriter (4 Commercial Criteria (4CC)) belirlemesi dikkate değerdir. Buna göre, uyulacak temel ilkeler şöyle sıralanmaktadır: "BBC'nin Kamu Amaçlarına uygun olmak; BBC'nin iyi itibarını veya $B B C$ markasının değerini tehlikeye atmamak; ticari verimlilik göstermek; ve Adil Ticaret Politikasına Güven'e, BBC'nin Adil Ticaret Klavuzu'na uymak, ve özellikle pazarı bozmaktan sakınmak" (akt. Johnson, 2013, s.317). Bu kriterler BBC’nin pazarın gerekliliklerini dikkate alarak ticari faaliyetlerini sürdürme çabaları ile bu tür faaliyetlerini kamu hizmeti yayıncılığının kalite ve güvenilirlik ilkeleri temelinde gerçekleştirdiğini gösterme çabaları arasındaki gerilimli ilişkiyi yansıtır niteliktedirler. Ayrıca ticari faaliyetlerinin pazarı bozmaması konusundaki hassasiyeti, daha temelde kamu hizmeti yayıncılarına yöneltilen ayrıcalıklı konumlarıyla piyasanın işleyişini ve rekabet koşullarını bozdukları yönündeki eleştirilere daha fazla maruz kalmama isteğini akıllara getirmektedir.

Bu noktada, kamu hizmeti yayıncılarının karşısındaki temel sorun markalaşma sürecinde kamu hizmeti ilkelerini oluşturdukları markanın temeline koyup koymamalarında ya da daha önce değinildiği gibi marka imajlarının kamu hizmeti yayıncılığı ilkelerine ne kadar uyumlu olacağında düğümlenmektedir. Bu ilkelerin ve değerlerin kamu hizmeti yayıncilığının tarihsel köklerinden gelen en temel mirası olduğunu belirten Lowe ve Palokangas, kamu hizmeti yayıncılarının markalaşma sürecinde kendi yayıncılık köklerinden gelen miras değerlerini korumalarının ve markalarını bu mirasın üzerine inşa etmelerinin önemine işaret etmekte ve bu çerçevede "miras marka yönetiminin (heritage brand management)" kamu hizmeti yayıncıları açısından ihmal edilmemesi gereken bir "stratejik marka yönetimi" biçimi olduğuna vurgu yapmaktadırlar. Onlara göre, kamu hizmeti yayıncılarının markaları açısından çok değerli bir ürün olan böyle bir mirası kullanmak oluşturulacak markayı yalnızca ticari hedefler 
açısından değil kamu hizmeti yayıncılığının dayandığı kamusal ve kültürel hedefler açısından da değerli kılacaktır. Bu süreçte kamu hizmeti yayıncıları insanları birer müşteriden ziyade vatandaş olarak gören ve sosyal sorumluluğu ön plana çıkaran yayıncılık miraslarına değer veren bir markalaşma yönelimine girmelidirler. Bu anlamda, kamu hizmeti yayıncıları kurumsal markalarını birer "vatandaş markası" olarak inşa etmelidirler. Çünkü onlara göre, en başarılı markalar insanı ve toplumu markalarının merkezine koyma eğilimindedirler (2010, s.129-139). Bu temelde, günümüzde kamu hizmeti yayıncilı̆ıının yenilenmesi "temel olarak yeni medya teknolojilerine hâkim olmakla değil; sosyal meşruiyetin yeniden geliştirilmesi için temel değerleri yeniden canlandırmakla ilgilidir". Bunun için de dikkat etmeleri gereken temel nokta özellikle yöneticilerinin hâkim piyasa mantı̆̆ını benimsememeye ve kendilerini rekabetçi koşullara kaptırmamaya, pazar bağımsızlığını ve sosyal sorumluluğu temel alan bir yönetim anlayışını sürdürmeye özen göstermelerinde yatmaktadır (Lowe ve Palokangas, 2010, s.135, 138). Başka bir deyişle, ticari önceliklerin kamu hizmeti yayıncılı̆̆ markasının dayandırıldığı temel ilkeleri aşındırabileceğinin ve hata bunları geri plana atabileceğinin (Steemers, 2003, s.134) farkında olan bir yönetim anlayışını benimsemek önem taşımaktadır.

Bu tür bir anlayışa yapılan gönderme Wæraas'ın daha genelde tüm kamu hizmeti kurumlarının çeşitlilik gösterebilen ve farklılıkları dikkate alan bir markalaşma stratejisi benimsemelerinin önemine yaptığı vurguyu akıllara getirmektedir. Wæraas, kamu kuruluşlarının "toplumdaki çoğu zaman çelişen değerlerin ve ihtiyaçların yönetişimine katılmaları ve meşgul olmaları gerektiği için" birbirinden farklı ve birbiriyle çelişik görünen çoklu değerlere ve kimliklere sahip olduklarını, bu durumun bütünlüklü tek bir marka inşa etmede de zorluklar doğurduğunu belirtmektedir. Ona göre, bu noktada önemli olan bu kurumların bütün değerlerini kapsayıc1 bir bakış benimsemeleri ve tek bir kurum markası konumu bulmaya çalışmak yerine farklılıklar gösteren tüm değerlerini dikkate alan ve hatta bu çeşitliliği arttıran bir markalaşma yönelimini temel almalarıdır (2008, s.217-218). Born, BBC’nin gençlere yönelik yayınlarında farklı bir kesime ve farklı beklentilere hitap etmekten kaynaklanan bu tür çelişkilerle karşı karşıya kaldığına değinmektedir. Gençlere yönelik bazı programların BBC’nin ana markasıyla çelişen nitelikler taşıdığını belirtmektedir. Bu noktada, ona göre temel soru BBC'nin “çelişkileri alt markalarıyla çalışmak için nasıl kullanılacağı veya genel şirket markasını nasıl değiş̧tireceği”" temelinde şekillenmektedir (Born, 2005, s.298). Born'un bu vurgusu kamu hizmeti yayıncılarının markalaşma stratejilerinde kamu hizmeti ilkelerini geliştirme ve hayata geçirme potansiyelini ön plana çıkarma ile ekonomik öncelikler ve kaygılarla piyasaya pratiklerini benimseyerek bunları geri plana itme riski arasındaki gerilimli ilişkiyi aşmalarının pek de kolay olmayacağını düşündürtmesi açısından önem taşımaktadır.

\section{Sonuç}

Tüm bu tartışmaların izi sürüldüğünde kamu hizmeti yayıncıları açısından markalaşmanın anlamı ve önemine dair bir değerlendirme yapmanın zorluğu ortaya çıkmaktadır. Piyasa ilişkileri ve rekabet koşulları karşısında savunmasız kalma olasilığı arttıkça bu kuruluşların markalaşma stratejilerinin ekonomik kaygılar açısından temel bir rol üstlenebileceği söylenebilir. Ancak, bu durum, kamu hizmeti yayıncılı̆̆ anlayışına piyasa mantığının her geçen 
gün daha fazla hâkim olması riskini beraberinde getirmektedir. Bununla birlikte, kamu hizmeti yayıncılarının yeni koşullara uyum sağlayarak varlıklarını sürdürebilmelerinin yolunun piyasa mantığını ve pratiklerini benimsemelerinden geçtiğine dair bir anlayışın kabul görmesi bu kuruluşların markalaşma stratejilerini daha çok ticari öncelikler açısından değerlendirmelerine yol açmaktadır.

Oysa, daha önce de değinildiği gibi, markalaşma kamu hizmeti yayıncıları açısından yalnızca ekonomik öncelikler ve ticari bir mantıkla ele alınamayacak anlamlar da taşımaktadır. Kamu hizmeti yayıncılarının markalaşma çabalarında asıl önemsemeleri gereken noktayı da burası oluşturmaktadır. Medya sektörünün karmaşık yapısının arttığı, farklı mecralar aracılığıyla faaliyet yelpazesinin hızla genişlediği ve bu nedenle izleyici yapısının sürekli farklılaştığı bir ortamda gerek bütünlüklü ve görünürlügü yüksek bir kimlik oluşturmada ve gerekse izleyicilerle ilişkileri sürdürmede markalaşmanın ve marka stratejilerinin önemi her geçen gün artmaktadır. Bu noktada, oluşturulan markanın hangi temel değerlere dayandırılacağı büyük önem taşımaktadır. Lowe ve Palokangas (2010) ve Johnson (2013) gibi isimlerin kamu hizmeti yayıncılarının oluşturdukları markaları uzun tarihsel köklerinden gelen kamusal değerlere ve ilkelere dayandırmaları yönündeki önerileri bu açıdan anlamlıdır. Çünkü kamu hizmeti yayıncıları piyasa aktörlerine benzedikleri ölçüde değil, aksine onlardan farklılaştıkları ve kamu hizmeti yayıncılığı ilkelerini hayata geçirmenin yolarını aramaya devam ettikleri ölçüde yayıncılık alanında önemli bir konum edinebilirler. Bu anlamda, inşa ettikleri markaları kamu hizmeti yayıncılı̆̆ı anlayışından gelen kendi kamusal-kültürel değerleri çerçevesinde ele almaları ve şekillendirmeleri temel bir gereklilik olarak belirmektedir. Bunun için de ticari önceliklerin ve piyasa mantığının bu noktayı gözlerden kaçırma potansiyelinin farkında olan bir marka yönetimi anlayışını benimsemek önem arz etmektedir.

\section{Kaynakça}

Bardoel, J. ve d'Haenens, L. (2008). Reinventing Public Service Broadcasting in Europe: Prospects, Promises and Problems. Media, Culture and Society, 30(3), 337- 355.

Bennett, J. ve Strange, N. (2008). The BBC's Second-Shift Aesthetics: Interactive Television, Multi-platform Projects and Public Service Content for a Digital Era. Media International Australia, 126, 106-119.

Born, G. (2003). Strategy, positioning and projection in digital television: Channel Four and the commercialization of public service broadcasting in the UK. Media, Culture and Society, 25(6), 773-799.

Born, G. (2005). Uncertain Vision: Birt, Dyke and Reinvention of the BBC. London: Vintage. Brand Finance (2012, Mart). Brand Finance Global 500: The Annual Report on the World's Most Valuable Brands. 
Brand Finance (2018, Şubat). Brand Finance Global 500 2018: The Annual Report on the World's Most Valuable Brands.

Brand Finance (2018, Nisan). Brand Finance United Kingdom 150, 2018: The Annual Report on the Most Valuable British Brands.

Curran, J. ve Seaton, J. (2003). Power Without Responsibility: The Press and Broadcasting in Britain. London, New York: Routledge.

Debrett, M. (2009). Riding the Wave: Public Service Television in the Multi-platform Era. Media, Culture and Society, 31(5), 807-827.

Donders, K. ve Raats, T. (2015). Public Service Media and European Market Integration Policies. Karen Arriaza Ibarra, Eva Nowak ve Raymond Kuhn (ed.), Public Service Media in Europe: A Comparative Approach içinde (s.53-72). London and New York: Routledge.

Enli, G. S. (2008) Redefining Public Service Broadcasting Multi-Platform Participation. Convergence: The International Journal of Research into New Media Technologies, 14(1), 105-120.

Goddard, P. (2017). 'Distinctiveness' and the BBC: a new battleground for public service television? Media, Culture and Society, 39(7), 1089-1099.

Gromark, J. ve Melin, F. (2013). From Market Orientation to Brand Orientation in the Public Sector. Journal of Marketing Management, 29(9-10), 1099-1123.

Herzog, C., Hilker, H., Novy, L. ve Torun, O. (2017). Transparency and Funding of Public Service Media. Wiesbaden: Springer.

Hoynes, W. (2003). Branding Public Service: The "New PBS" and the Privatization of Public Television. Television and New Media, 4(2), 117-130.

Hujanen, T. (2004). Public Service Strategy in Digital Television: From Schedule to Content. Journal of Media Practice, 4, 133-153.

Iosifidis, P. (2010). Pluralism and Funding of Public Service Broadcasting across Europe. Petros Iosifidis (ed.), Reinventing Public Service Communication: European Broadcasters and Beyond içinde (s. 23-35). London: Palgrave Macmillan.

Jakubowicz, K. (2007). Public Service Broadcasting: A Pawn on an Ideological Chessboard. Els De Bens (ed.), Media Between Culture and Commerce: Changing Media-Changing Europe Series Volume 4 içinde (s.115-150). UK/Chicago, USA: Intellect.

Johnson, C. (2007). Tele-Branding in TVIII. New Review of Film and Television Studies, 5(1), 5 24. 
Johnson, C. (2013). From brand congruence to the 'virtuous circle': branding and the commercialization of public service broadcasting. Media, Culture and Society, 35(3): 314331.

Lury, C. (2004). Brands: The Logos of the Global Economy. London and New York: Routledge.

Lowe, G. F. ve Palokangas, T. (2010). Heritage Brand Management in Public Service Broadcasting. Petros Iosifidis (ed.), Reinventing Public Service Communication: European Broadcasters and Beyond içinde (s. 128-142). Basingstoke: Palgrave Macmillan.

Martin, F. ve Lowe, G. F. (2013). The Value and Values of Public Service Media. Gregory Ferrell Lowe ve Fiona Martin (ed.). The Value of Public Service Media içinde (s. 19-40). Göteborg: Nordicom University.

Moe, H. (2010). Governing Public Service Broadcasting: "Public Value Tests" in Different National Contexts. Communication, Culture and Critique, 3, 207-223.

Moe, H. ve Van Den Bulck, H. (2013). Comparing 'Public Value' as a Media Policy Term in Europe. Gregory Ferrell Lowe ve Fiona Martin (ed.). The Value of Public Service Media içinde (s. 57-76). Göteborg: Nordicom University.

Moor, L. (2007). The Rise of Brands. Oxford and New York: Berg.

Murdock, G. (2004). Building the Digital Commons: Public Broadcasting in the Age of Internet. The 2004 Spry Memorial Lecture, University of Montreal.

Murdock, G. (2005). Public Broadcasting and Democratic Culture: Consumers, Citizens, and Communards. Janet Wasko (ed.), A Companion to Televisio içinde (s. 174-198). Oxford: Blackwell.

Murdock, G. (2018). Reclaiming Digital Space. From Commercial Enclosure to the Broadcast Commons. Gregory Ferrell Lowe, Hilde Van den Bulck, Karen Donders (ed.), Public Service Media in the Networked Society içinde (s. 43-58). Göteborg: Nordicom.

Scannell, P. (2001). Public Service Broadcasting: The History of a Concept. Andrew Goodwin ve Garry Whannel (ed.), Understanding Television içinde (s. 11-29). London and New York: Routledge.

Sorensen, I. E. (2014). Channels as Content Curators: Multiplatform Strategies for Documentary Film and Factual Content in British Public Service Broadcasting. European Journal of Communication, 29(1), 34-49.

Steemers, J. (1999). Between Culture and Commerce: The Problem of Redefining Public Service Broadcasting for the Digital Age. Convergence, 5(3), 44-66. 
Steemers, J. (2003). Public Service Broadcasting is not Dead Yet. Strategies in the 21st Century. Gregory Ferrel Lowe ve Taisto Hujanen (ed.), Broadcasting and Convergence: New Articulations of the Public Service Remit içinde (s. 123-136). Göteborg: Nordicom.

Van Den Bulck, H. (2015). Public Service Media Accountability in Recent Decades: A Progressive Shift from State to Market. Karen Arriaza Ibarra, Eva Nowak ve Raymond Kuhn (ed.), Public Service Media in Europe: A Comparative Approach içinde (s. 73-88). London and New York: Routledge.

Wæraas, A. (2008). Can public sector organizations be coherent corporate brands? Marketing Theory, 8(2), 205-221. 